DOI: $10.20472 / B M .2015 .3 .4 .002$

\title{
TRANS-NATIONALISATION OF A MAIN OFFICE IN A MULTINATIONAL FIRM
}

\section{FUMIHIKO ISADA, YURIKO ISADA}

\begin{abstract}
:
The purpose of this research is to prove quantitatively whether the transformation of the international business model of a Japanese multinational firm has influenced the trans-nationalisation and diversity in the main office in Japan. Moreover, it is proving quantitatively the influence of the management on the move-in region by trans-nationalisation and diversity of a Japanese main office. According to the previous research, it was traditionally one of the big traits of the personnel system of a Japanese multinational firm that trans-nationalisation of employment does not progress as compared with a European or American company. However, the consciousness of the top managers of a Japanese multinational firm is changing recently. The top managers of Japanese multinational firm recently faced the big transformation of the management environment that an emerging-countries market grows up rapidly, while the Gross Domestic Product of Japan fell to the third in the world. As a research methodology, a questionnaire was given to the multinational firms which has advanced to emerging countries. In conclusion, it was verified that trans-nationalisation of a main office has progressed because the international business model in the emerging countries of a Japanese firm converted. Moreover, it was verified that trans-nationalisation of a main office has promoted the relationship with various stakeholders in an emerging country as an effect on management.
\end{abstract}

\section{Keywords:}

international business model, trans-nationalisation, Japanese multinational firm, emerging country, questionnaire

JEL Classification: M16, M14, M10

\section{Authors:}

FUMIHIKO ISADA, Kansai University, Japan, Email: isada@kansai-u.ac.jp

YURIKO ISADA, Kwansei Gakuin University, Japan, Email: yuriko@kwansei.ac.jp

\section{Citation:}

FUMIHIKO ISADA, YURIKO ISADA (2015). Trans-nationalisation of a main office in a multinational firm. International Journal of Business and Management, Vol. III(4), pp. 15-40.,

10.20472/BM.2015.3.4.002 


\section{Introduction}

The purpose of this study is to provide empirical clarification about the relationship of a transformation of the international business model of a Japanese firm and diversity and trans-nationalisation of a Japanese main office. As a classic example of the international business model in the high economic growth period from the 1960s to around the 1970s, the Japanese firm had adopted the processing trade model. It is a model which earns foreign money by importing various scarce industrial raw materials in Japan and massproducing and exporting the manufactured product of good quality at a low cost. This model was premised on the existence of the large-quantity young labour layer homogeneously educated in middle rank. Then, in connection with a strong yen against the dollar ignited by the Plaza accord in 1985, the Japanese manufacturing firm converted the international business model from the exportation model and advanced overseas relocation of the production district. Many Japanese multinational firms were the global corporation models by the definition of Bartlett and Ghoshal (1999). It is a model which centralises in a parent nation, develops and holds knowledge in a parent nation, and spreads the strategy of a parent nation on a global scale. Although the international business model converted into the global model and trans-nationalisation and diversity of the recruitment progressed in the overseas subsidiary, the diversity in Japan seldom changed. This homogeneity may have contributed to improving the coherence inside and outside of an organisation in a research and development activity or a productive activity, and increasing an international competitiveness in the industry segment, which adopts the product architecture of an integral style like a motorcar, for example. On the other hand, various problems were generated about a human resource management of an overseas subsidiary, etc.

Probably one of the biggest transformations of the external environment which affects the international business model in this century is an evolution of an emerging-countries economy. In the traditional international business model of a Japanese firm, the low cost and high-performance product has mainly been mass-produced and supplied towards the lower layer volume zone of the market in the countries of a standard of living higher than Japan's, such as European and American advanced nations. However, in regard to the low cost and high-performance manufactured product, the competitive advantage of the Japanese firm was lost by the appearance of many rival firms with the growth of an emerging-country economy. Therefore, many Japanese firms are trying to find a new competitive advantage which differs from the former, especially in an emerging market. In the traditional international business model of a Japanese firm, emerging countries including Southeast Asia were positioning the production district, which supplies a cheap working force, etc. Thus, emerging countries came to be regarded as the mainly huge market where growth is expected. In an emerging market, since there is no chance of winning by a simple price war, developing and supplying the product and service of a 
high value-added, complicated, and imitation difficulty in accordance with local needs is required. For that purpose, the source of the competitive advantage cultivated originally in the parent nation alone is not enough. It becomes useful by grasping the real situation of the region and cooperating with local government authorities or various stakeholders to create and grow a market. Many European and American multinational firms are excellent about the international business model by the comparatively long-term viewpoint in such an emerging country. For example, trans-nationalisation of the recruitment in a parent nation is considered to have backed up creation and expansion of the market in emerging countries. Additionally, in the primary multinational firms of Japan, trans-nationalisation of the recruitment in the main office of a Japanese firm has recently come to be covered widely in the mass media. For example, traditionally, Panasonic, which is one of the major electric manufacturers, has recruited the Japanese new graduate en masse on the assumption of long-time employment. On the other hand, as a general rule, the foreigner has been employed on the assumption of mid-career recruitment, a short term, and a definite period. Panasonic is recently trying to lose such a distinction.

This research intended to verify empirically such a transformation of the international business model of the primary multinational firms of Japan. The questionnaire was given to the Japanese multinational firms which are moving into the emerging market. Two research questions were mainly verified quantitatively. One is clarifying the relationship of the difference in an international business model and the diversity of a main office. International business models are the traditional exportation model of manufactured products and production district model, and the mid- and long-term localisation and market creation/expansion model. The second is clarifying what kind of business results in a move-in country are raised by the trans-nationalisation and diversity of the recruitment in a main office.

\section{$2 \quad$ Precedence research}

\section{2-1. Human resource management of a multinational firm}

In management functions, it has been pointed out by previous research that personnel function has a high extent of decentralisation (e. g., Harzing, 2001). It is because a market for labour, a labour view, Employment Relations Law, etc. change with a country or regions. On the other hand, the global integration about International Human Resource Management (IHRM) is also required for a multinational firm at the same time. The trait with which IHRM differs from human resource management (HRM) for a national corporation is coping with the complexity of performing the tune-up across the border through overseas relocation of business modality or management practices for the human resource of two or more countries (e. g., Dowling, 1988; De Chieri \& Dowling, 2006; De Cieri et al., 2001; Gregersen \& Black, 1996; Morgan, 1986). Franko (1973) has indicated that an executive person's nationality politics in a global corporation changes 
with the phase of an internationalisation of a company based on the investigation of actual conditions of a European and American company. That is, it is divided into five phases - simplicity exportation, local-production beginning, overseas production expansion, local main office, and global - and the nationality of executive persons were studied. It is advantageous to appoint the natives as the top of an overseas subsidiary from standpoints of the benefit and cost, such as "cost concerning sending of a representative and the re-integration after return to its post", "the natives' motivation", and "an amalgamation for a local society and a Government authorities". Such a personnel policy is the strong point and subject of a multinational firm.

According to Doz et al. (2004), it is becoming difficult for a global corporation to build a global competitive advantage based only on technical development ability in a parent nation; production of scientific technology knowledge has decentralised and become global. Against such a background, the viewpoint of "meta-national innovation" has come to attract attention. The general policy conventionally employed in order to increase new products' probability of success was to further heighten internal research and development capability by investing in further research and development and efficient staff. However, the research and development investment efficiency was falling with only internal capability because of the transition of a global competitive environment. The global corporation has been pressed to employ research and development efficient staff from locals regardless of their nationality. As a result, a global corporation needed to possess the knowledge of various cultures as organisational capability. Activity which approaches and integrates market characteristics from various viewpoints is required so that a new product development project can target a major overseas market. A project leader needs the capability to understand and integrate the various cognitive contexts based on project members' cultural diversity. A project leader is also required to have more advanced meta-cognition and multicultural management capabilites, as the mission of a new product development project is to aim at global competitive advantage. As competition is international, radical innovation based on various technical bases is more needed. In order to develop the product of new concepts based on various technologies, technical collaboration capability with various external organisations becomes absolutely necessary.

\section{2-2. The subject of a multinational person management of a Japanese firm}

Oddou et al. (2001) show the international trait in the training procedure by international comparison of the global personnel-training measure. In the survey, the variance analysis compares the result of the questionnaire survey for the global corporations which have a main office in Japan, the United States, and Europe which were chosen as the Fortune 500. From the results of an investigation, it is shown as a trait of a Japanese global corporation that the frequency of hands on training by the overseas business trip and residence to a Japanese worker is high compared with a European or American company. Moreover, although the European and American companies had appointed 
many foreign executives, foreign executives were very few in the Japanese main office. And it was proposed that the global-network formation and global personnel training by an international collaborative work, such as international task force or a project team, are useful for a global corporation including a Japanese firm as a future direction. Fukao (2006), Kamata (2006), Nonaka (2004), Shiraki (2006), and Suzuki (2005) have indicated that localisation of the person of a Japanese firm, especially a top manager's localisation, are behind compared with European and American companies. Moreover, it is claimed that a revision of the wage system of the local subsidiary of a Japanese firm is necessary. Various problems have occurred by such a delayed localisation strategy.

Amuro (1982) has used the notion of the context by Hall (1976). A context means the prerequisite shared by those which communicate. Hall (1976) analysed primary cultural traits from the information content included in a language, classified Japan with the high context culture, and classified the United States and Germany with the type of the low context culture. Since the percentage of completion of the prerequisite shared in a high context culture is high, clear-statement-ising and the coded notice can be managed with necessary minimum. On the other hand, a clear linguistic expression is needed by the communication in a low context culture. The Japanese firm which has developed under a high context culture has much tacit knowledge of management. Therefore, in the overseas business deployment, a transference and control of a technique or a scheme are achieved through the Japanese representative well versed in the system of an organisation. On the other hand, in the European or American company on condition of a low context surrounding, primary operation knowledge is formulated in the form of the job description, the manual, the trans-missive system, the budgeting system, etc. These are the compilations of knowledge which the organisation has acquired, as well as the mechanisms of a control. Therefore, the primary mission of the personnel sent from a main office is inclusion of a control mechanism. Once a control mechanism is incorporated, the management of an overseas subsidiary is manageable by measurement of a total numerical notice or an operation result. Amuro (1982) argues that such indirect control localises easily. It is because the direct and indirect selection about the supervision of an overseas subsidiary has a close relationship to the number of overseas dispatch persons.

According to the survey of Hayashi (1994), the undertone of a culture is a high context originally in Asia and African countries. However, in countries other than Japan, the low context style management is dominant as a result of being exposed to the intense influence of Europe and America before the operating style based on oneself culture was developed. There is almost no country where a high context style is dominant in the management of an enterprise except Japan. Therefore, the high context style of the Japanese firm is a major factor which delays localisation. For example, in the organisational operation of a Japanese firm, a responsibility is decided roughly and leaves the judgment according to the status of an individual. It functions in the Japanese 
main office which has raised such a working staff by OJT or a rotation since entrance. However, it becomes a traverse towards localisation that the natives' working staff has not passed through such a training process overseas.

Yoshiwara (1989) has taken up internationalisation at home as one factor of the lag in localisation. Internationalisation at home is an internationalisation of the parent company, and is about the condition of a foreigner's participation in the process of decision making in the parent company. Many presidents, board members, or department managers of the parent company of a Japanese firm were in domestic operation lines, and the executive who is experienced overseas is still a minority. Moreover, the local workforce of overseas affiliated firms had barely participated in processes in which important management strategies and plans are drawn up. The Japanese also exchanged information between a parent company and an overseas affiliated firm in Japanese in many cases. Such conditions of a parent company had been the barriers to the localisation of Japanese firms. Even if the local workforce was able to communicate in a foreign language, such as English, it was difficult for the parent company side to respond in many cases. Yoshiwara used a questionnaire for Japanese firms in order to verify the relationship between localisation and internationalisation at home. As a result, the number of Japanese employees/board members who are experienced overseas, and the number of foreign employees employed in the Japanese head office, are positively correlated with localisation.

\section{2-3. A transformation of the latest Japanese firm.}

A conscious transformation of the top manager of a Japanese firm is observed in recent times. For example, according to the questionnaire which the Japanese Business Federation (2011) carried out, the number of effective answers is 584, and the following results of an investigation are shown. 40 percent of the companies answered to expand recruitment and training of the Japanese on condition of foreign posting about the globalisation of a future business. On the other hand, the answer of appointing a qualified person to be an executive regardless of nationality also showed $30 \%$. The Japanese firms seems to desire managerial talent who can demonstrate capability with global management regardless of a nationality from now on. Moreover, it is answered that half of Japanese firms carry out a transfer and placement according to the demand of positions regardless of nationality. Similarly, half of Japanese firms have answered that they offers the opportunity of a promotion and preferment equally regardless of nationality. When many Japanese firms advance global personnel training, they seem to plan to appoint foreign able persons other than a Japanese positively.

\section{2-4. The influence of trans-nationalisation on an innovation}

According to prior research, it is possible to promote an innovation, contribute to the advancement of an industrial structure, and realise economic growth by employing the foreigner who has advanced technique and skill. Moreover, the complementary 
relationship between the working force which has advanced technique and skill and a capital with high productivity is effectuated. Otherwise, it is verified that the statistics relevant to innovations, such as the patent taking number of items, are increasing by accepting highly skilled foreign professionals. Accepting the foreigner as a highly skilled professional has an impact on an innovation. For this reason, in each country, the courtesy politics and selective immigration policy to highly skilled professionals are implemented. According to Chaloff and Lemaitre (2009) and OECD (2013), in addition to the United States, Canada, Australia, and New Zealand, which are emigrant nations, the preferential treatment to a height educational emigrant is introduced even in Britain, Denmark, and the Netherlands in recent years. It is expected that such a trend will continue, and qualified person hiring competition further intensifies. Foreign qualified persons' acceptance especially leads to a promotion of an innovation in the researchand-development field. According to Giovanni (2007), 26\% of Nobel Prize winners in the United States in the 1990s were emigrants, and it was a high ratio as compared with $12 \%$ of the foreigner population. According to Anderson and Platzer (2006), 25\% of the entrepreneurs who received public support in the United States from 1990 to 2005 were emigrants. According to Wadhwa et al. (2007), in 2006 25\% of the entrepreneurs of the tech company whose sales were 1 million dollars or more were emigrants. According to Kerr (2010a), 12\% of the aggregate numbers of the patent taking by 2004 were from in persons of Chinese, Taiwanese, and Indian origin. Additionally, $24 \%$ of the number of international patent takings from the United States are acquired by non-Americans. The foreigner has contributed to the upsurge of the U.S. patent share. According to Cervantes and Guellec (2002), Freeman (2006), Kerr (2008), and Kerr and Lincoln (2010), the U.S. economy of the 1990s grew because of the activity of emigrants from Asia within the technology field.

Berliant and Fujita $(2011 ; 2012)$ show clearly that, theoretically, diversity contributes to innovation. As a result of a model simulation, people's knowledge does not produce a synergy effect, even if two or more of the same things gather, but a synergy effect is born by able persons with a mutually different body of knowledge. In addition, in order for people to share knowledge of a different kind mutually and to form new knowledge, a common language, a common knowledge, or a common area of interest are also required. Furthermore, the suitable extent of a diversification exists. According to Peri (2007), Zucker and Darby (2007), Hunt and Gauthier-Loiselle (2010), Kerr (2010b), and Kerr and Lincoln (2010), an innovation is urged by accepting the foreigner with a high level of education from overseas. According to Niebuhr (2010), Ottaviano and Peri (2006), Ozgen et al. (2011; 2012; 2013), and Sudekum et al. (2009), if diversity progresses, a higher innovation level will be attained. According to Herring (2009), diversity is making the sales, emolument, and number of customers of the company increase significantly. Racial diversity was making sales, the number of customers, the market share, and the emolument increase, and sex diversity was also making sales, the number of customers, and the emolument increase, as a result of analysing the influence 
which the diversity in race and sex has on corporate performance in the United States. Thus, in many studies it is concluded that diversity promotes innovation.

In the IT sector, the research is accumulated about a foreign worker's receipt and the impact on innovation. Kerr and Lincoln (2010) make the trial calculation that more than half of system engineers (SE), which increased in the United States in 1995 and afterwards, is an emigrant. According to Hunt and Gauthier-Loiselle (2010), many immigrants who become SE workers have a high level of skill. According to Stephan and Levin (2001), in the United States the foreigner contributes to the expansion of the technology field. Since the foreigner who received the advanced education outside the United States has contributed to the United States, the United States has got the benefit by brain drain from overseas. In relation to this, loannidis (2004) analysed using the cross-section data of 1523 researchers by whom the thesis is quoted at the high frequency in Institute of Scientific Information (ISI). As a result, 1/3 of researchers are doing their present research in a different country from the country of birth, and 3/4 of them were doing research in the United States. According to Hunter et al. (2009), about half of the prominent physicists in the world work in countries other than their country of birth. Such a scholar can be attracted by a country with much capital for research and development.

On the other hand, according to Alesina and La Ferrara (2005), who carried out a survey of the relationship of an innovation to the foreign worker, the relationship of plus and the relationship of minus are verified by the research. According to Ozgen et al. $(2011 ; 2012$; 2013), it has also observed that innovation decreases when the ratio of a foreign worker becomes too large. According to Berliant and Fujita $(2011 ; 2012)$, an innovation will become difficult to increase if diversity progresses too much. Lee and Nathan (2010), Mare et al. (2011), Niebuhr and Peters (2012), Ostergaard et al. (2011), and Parotta et al. (2011) have arrived at the same conclusion. Thus, it is thought that there are conditions in order for diversity to raise innovation.

\section{2-5. The BOP market}

According to Hart and Sharma (2004), since much of the previous research on international business has targeted the activities of local subsidiaries in developed countries, there is no telling whether the theory can be applied to a developing country (probably only a TOP layer is applicable in the former case). In order to complement the previous research, the new concept of radical trans-activeness (RT) with dynamic capability has been developed. This capability is defined as the capability systematically to authorise, search for, and integrate the viewpoint of the stakeholder at the fringes in order to respond to the destructive transition in a developing country's market. The stakeholders in developing countries' markets are divided into core stakeholders and fringe stakeholders. The former comprise investors, customers, government authorities, competitors, employees, non-governmental organisations, suppliers, communities, etc.; 
the latter stakeholders are the poor, socially vulnerable, isolated, uninterested, nonlegitimate, etc. In order for a company to enter a BOP market, both core stakeholders and fringe stakeholders need to be involved and to have full knowledge of confrontations and conflicts. RT is the capability to explore business potential, building a relationship with fringe stakeholders, opening up the framework of knowledge development and experience and considering social constraints and potentialities.

In London and Hart (2004), the capability necessary for BOP market entry was inductively verified based on 24 cases. Global capability was analysed in terms of three aspects: collaboration with an unorthodox partner, custom-made solution co-creation, and construction of local capacity. This capability is almost synonymous with the abovementioned RT dynamic capability. There is variation in the necessary conditions for these three capability groups between successful and unsuccessful companies in a BOP market, and they influence the growth potential in a lower-layer market. When entering a BOP market, a company cannot depend on the transfer or protection of the knowledge or resources developed in the TOP market. Additional capabilities are needed to surpass those used in TOP markets, such as conventional global operational efficiency, local adaptability, and existing knowledge transfer. When entering a BOP market, an effective strategy is for a company to understand the social context and to specify and use its strengths in the business environment concerned. Moreover, a strategy built through a bottom-up process and sharing resources across organisational boundaries is effective. A company with a high capability for social embedding can easily be successful.

\section{2-6. Creation of shared value}

The creation of shared value (CSV) has been advocated by Porter and Kramer (2011). A company raises social value by meeting social needs through internalising external diseconomies, such as environmental pollution, water pollution, or traffic congestion. A company raises economic value, such as sales or profit, through Cooperate Social Responsibility (CSR) as a primary business. CSV is a concept which shares both values: it is a management concept which reconciles social business solutions, business income, and improvement in competitiveness, but it also yields a value both to society and the company. The resolution of social issues by a business offering value is added to strategic CSR and integrated into it as CSV. CSV is proposed as a different concept from CSR. Generally, CSR tends to be realised in terms of alleviating the adverse effects of an enterprise activity, or as philanthropic activities. Therefore, it seems that business administrators tend to accept CSV by advocating it as a different concept from CSR. Although it is difficult to express the effect of CSR in numerical terms, the effect of CSV is expressed numerically as profit to the company.

CSV essentially has three dimensions. First, it is an offering of a product or service which solves a social issue. Second, in it, competitive enhancement of a value chain and a contribution to society coexist. Third, enhancement of the competition base in a corporate 
development region and the contribution to the region coexist. An example of a business engaged in CSV would be a company working on one of the renewable energies important for the diversification of energy sources or the battle against global warming. Equally, BOP business - which, for example, might develop a customer base of four billion people living on less than $\$ 2$ per day and seek to meet their needs - in many cases operates based on the spirit of CSV. The success of the company's business is also achieved by solving social issues, such as regional economy development, job creation, or the eradication of sickness in a developing country. Such business enterprises for BOP markets can also be put into the category of CSV.

\section{2-7. Japan as a forerunner for addressing emerging problems in the world}

According to Komiyama (2007), the problems that come with industrialisation tend to surface earlier here in Japan than in other developed countries. In short, Japan is a forerunner in terms of the emerging social problems faced by advanced societies. Sooner or later, other countries are bound to face similar problems. As Japan becomes a mature nation and the demand for an artificial goods is being saturated. Durable consumer goods, such as cars, television sets, and air-conditioners are already common in Japanese households. Infrastructure constructions, such as roadways and water services, are also almost completed. These mean the shortage of internal demands in Japan. Since the desire for durable consumer goods is high in developing and emerging countries, many Japanese firms have turned to these overseas demands. However, the velocity of economic developments, such as in China and India, is quicker than the velocity which the present developed country has experienced. Also in these flourishing overseas-demand markets, the demand for an artificial goods will be saturated soon and the short demand will actualise. On the other hand, social problems in Japan, such as an increase of the aged population, disasters, and environmental problems, have arisen beyond the foreign country. Those social problems are likely to be faced someday even in emerging countries, such as those in Asia. Since the Japanese firm is tackling those settlements, it can offer the knowledge which is useful to each country. Contributing to emerging countries by the accumulation of experience and the element technology to solve social problems becomes a future international growth model of Japan, replacing the exportation model of saturated durable consumer goods. For example, Japan is resource-starved and its self-sufficiency rate of farming produce, etc., is low. Moreover, ahead of the rest of the world, population decline has begun. The scheme which solves these problems will probably be needed not only in a Japan but in the entire world. For example, in order to solve the problem of a scarcity of resources, energy-saving technologies such as a hybrid car have been developed. The demand for energy-saving functions outside of Japan is increasing due to a rise in environmental awareness, the rising cost of rock oil, etc. The exploitation of automation and safety techniques, including an industrial robot, is also useful in order to overcome the shortage of workers, a largescale accident, a miserable disaster, etc. 
In the past, the industry in Japan introduced European and American products and business models, arranged them in the style of Japan, and exported them. Now, the Japanese industry is searching for a "problem forward-country" model, and will transfer the problem solution overseas. In the traditional model, the Japanese firm took in the existing standards of every country in the world, compared them, improved them, and pursued the profit. A "problem forward-country" model aims at spreading and standardising the Japanese business solution technique and the procedure over the seas. The merits of global standardising are a market extension, a cost cut, and industrial development in the future. A standardisation strategy is deciding the platform of industrial development rather than a mere interchangeability and normalisation. Since the power of one company and one country is insufficient in order to form a standardisation, the formation of an alliance with the other company or a foreign country serves as a key factor which determines success or failure.

\section{2-8. Reverse innovation}

In the field of international business, the new role of an overseas affiliated firm has been paid attention to over the past ten years. Conventionally, the overseas affiliated firm has been considered to be a recipient of the advantage of its parent nation's main office (Dunning, 1979; Hymer, 1970). However, an advantage of an overseas affiliated firm has attracted attention recently. According to the "meta-national management" view, an overseas affiliated firm is not dependent on the advantage of a parent nation; knowledge is acquired locally, and an advantage is acquired by spreading it globally (Doz et al., 2004). According to the Centre of Excellence's (COE) view, in a particular activity, an overseas affiliated firm becomes a central lodgement of a multinational firm (Frost et al., 2002). According to "reverse innovation," the innovation which the overseas affiliated firm yields affects developed countries, and the overseas affiliated firm bears a more important role (Govindarajan \& Trimble, 2012).

The notion of reverse innovation considers the potential of the BOP market strategy more positively than mere penetration at a local level. According to Immelt et al. (2009), two kinds of innovation - development in an emerging country and development for developed countries from an emerging country - are contained in reverse innovation. Product development adapted to the customer needs of the emerging country is indispensable, and the product also becomes an innovation which is adapted for the niche markets of developed countries. This means that product proposals which have until now failed to be adopted under a glocalization strategy are developed at the local emerging country level and subsequently offered in developed countries. That is, products that are not taken up under a glocalization strategy are developed through reverse innovation.

Glocalization is a strategy through which an excellent product is developed in the company's own country, is sold on the world market, and is partially changed according 
to local characteristics. In taking this approach, the trade-off between minimising costs through globalisation and maximising market share through localisation can be optimised. However, the development of the reverse innovation strategy has ended the period in which the glocalization strategy dominated. Like glocalization, though, if multinational firms do not recognise the capability of reverse innovation, it will be difficult for them to survive ten years from now or to ensure good earnings. Succeeding in an emerging country is a necessary condition for remaining prosperous in developed countries. Nonetheless, although the reverse innovation strategy is indispensable to business, the glocalization strategy is also important for the future. The problem is that they conflict with each other. Centralised product-focused organisational structures and management practices have led to the success of the glocalization strategy. Since the reverse innovation strategy aims at a regional market through a distributed structure, its character is the reverse of the glocalization strategy. It is necessary to overturn two beliefs. The first is that there is a flying geese pattern of development whereby developing country markets develop gradually, similarly to developed countries. In fact, in terms of introducing innovations, it is not unusual for an emerging market to leap ahead of developed countries. The second erroneous belief is that products that correspond to needs peculiar to an emerging country are deficient in terms of their competitiveness in developed countries. On the contrary, such products can create new markets in developed countries by virtue of being low-cost or leading the way in the development of new directions.

According to Govindarajan and Trimble (2012), as the development style of emerging countries is not the same as developed countries, models that succeed in developed countries cannot be applied to them. In order to meet the needs of an emerging country, it is important to achieve innovation at a local level from a zero base. In terms of management for implementing the reverse innovation strategy whereby the innovation evolves from an emerging country for global distribution, they identify five gaps between developed countries and emerging countries: performance, infrastructure, sustainability, regulatory, and preferences.

The performance gap: Since the consumers in an emerging country have little revenue, they require $50 \%$ of the solution at $15 \%$ of the price, rather than the localisation of a product oriented to developed countries. For example, in India, Nokia reduced the functions of its mobile telephones, but added the functions needed most at the local level, such as text messaging in Hindu and a powerful electric torch, and thus obtained more than $60 \%$ of the market share in India.

The infrastructure gap: In an emerging country, infrastructure is still under construction. The consumer in an emerging country requires solutions independent of existing infrastructure; as there is no tie to existing infrastructure, the supplier of improved infrastructure can adopt the latest solution immediately. An example of this is the highly successful low-cost battery-operated electrocardiogram meter developed by GE for India 
which can be used even if the electric power is unstable. In another example, a local telecommunications company in India jumped over the development step of a fixed-line telephone, promptly adopting radio technology instead and was successful.

The sustainability gap: Sustainability issues are particularly acute for emerging countries and they are anxious for next-generation environmental solutions. The market share for electric vehicles developed by BYD in China is growing.

The regulatory gap: As regulatory systems in emerging countries are still developing, they may benefit from a decreased time lag before an innovative solution is launched. For this reason, a new product may overcome regulatory hurdles when originated in an emerging country. Diagnostics for All, a non-profit organisation (NPO) which markets a new paperbased diagnostic method developed at Harvard University, succeeded in commercial production in emerging markets, whereas regulations prevented this in European and American countries.

The preferences gap: Every country has different tastes and preferences, and innovation needs to take such differences into consideration. In India, PepsiCo has experienced success producing snacks flavoured with herbs growing wild in Eurasia.

\section{2-9. Stakeholders and strategic alliance}

Freeman et al. (2004) defined the stakeholders of a company as groups or individuals who can affect the achievements of a company or who are influenced by it. The success of a company is realised through multiple stakeholders' mutual connection networks. Even if the interests of different stakeholders may be in opposition in the short term, the company has to harmonise them in the long term. In order for a company to pursue profit for those providing funding, it is necessary to create value for other interested parties, and fundamental to the profit-seeking approach is a sense of ethics. A company is successful as long as value is continuously created to the satisfaction of the main stakeholders. By defining the stakeholder concept, the concrete target of a company in terms of implementing social responsibility can be clarified and the goals of social responsibility can be realised.

According to Das and Teng (2000), a strategic alliance is the spontaneous collaboration between companies aimed at attaining a competitive advantage. Spekman et al. (1998) take the view that strategic alliances are close and long-term, and that there is reciprocity between plural partners in terms of sharing resources, knowledge, and capabilities with the aim of strengthening each partner's competition status. While networking between companies can be considered important, an alliance is embedded in the management strategy of a company and is expected to play a major role. Inkpen (1998) argued that for an alliance to evolve, ties between the partners which engender trust are important. From Larson's (1992) perspective, a business relation based on trust between organisations makes it possible for each to understand their partner's situation and to then achieve high levels of satisfaction and benefits. According to Bradach and Eccles (1989), when 
partners negotiate with mutual profit and loss and a companion's viewpoint in mind, trust increases further and this relationship is sustained on a long-term basis.

In terms of environmental issues, Stafford and Hartman (1996) contend that for a company to derive profit from pioneering the resolution of an environmental problem, a green alliance must be realised, taking a long-term outlook, and the strategic advantage of a win-win model must be built. According to Mendleson and Polonsky (1995), in engaging with environmental issues, alliance with an environmental NPO is important. When setting the environmental target of a company, in order to understand the environmental added value sought by consumers, alliance with an environmental NPO facilitates understanding of the consumer's viewpoint and potential needs, leading to market opportunities in the future and improvement in the organisational capability of a company. A continuous competitive advantage can be acquired by selecting a suitable environmental NPO. According to Hartman and Stafford (1997), a company can gain profit by initially entering a market with an environmental NPO. When turning an environmental problem into a strategic and attractive business, there must be integration of economic aspects and the social dimension of the resolution of the environmental problem. Through alliance with an environmental NPO, a company can gain public trust, together with the specialised knowledge necessary for the resolution of an environmental problem.

\section{Hypothetical derivation}

The purpose of this research is to first prove quantitatively whether the transformation of the international business model of a Japanese multinational firm has influenced the trans-nationalisation and diversity in the main office in Japan. Moreover, it is proving quantitatively the influence of the management on the move-in region by transnationalisation and diversity of a Japanese main office. According to the previous research, it was traditionally one of the big traits of the personnel system of a Japanese multinational firm that trans-nationalisation of employment does not progress as compared with a European or American company. In the research from the 2000 s, the status did not change a lot. The reason has been explained by factors such as the cultural identification of a high context style. Additionally, in companies in emerging countries within Asia and Africa, trans-nationalisation is progressing in response to the influence of European and American companies, and it can be said that the peculiar status has continued only in Japan. The status where such trans-nationalisation does not progress was the same in the personnel affairs of not only appointment of the management layer of an overseas subsidiary but a Japanese main office. Since what is called "internationalisation at home" is not progressing, this has caused various problems of international human resource management.

However, the top managers of Japanese multinational firm recently faced the big transformation of the management environment that an emerging-countries market grows 
up rapidly, while the Gross Domestic Product (GDP) of Japan fell to the third in the world. According to the questionnaire in a previous study, the consciousness of the top managers of a Japanese multinational firm is changing. Various studies have pointed out that diversity and trans-nationalisation can promote innovation in many cases. As the meta-national management theory has pointed out, it becomes a competition to combine and utilise the knowledge produced at various locations of the entire world in many directions. It is the same also in the relationship between a parent nation and emerging countries.

Of course the traditional international business model of a Japanese multinational firm about emerging countries may not deteriorate altogether instantly. For example, though the rate of growth of developed countries' markets, such as the West, is loose in comparison with emerging countries, the ratio in a global market scale is still large. A traditional international business model which exports the mass-produced goods produced by the low cost in the developing country to a developed countries' market is effective to some extent. For example, in an industrial electronic component, a highperformance material, etc., which has a high global-market share in a niche segment, probably, the motivation which converts a traditional international business model will not be strong, since a market size is not so large, while research and development takes time.

On the other hand, in the merchandise and service which are easy to be affected, especially in the trait of the market of an emerging country, it is possible that the traditional international business model of a Japanese multinational firm is pressed for a transformation. If the product itself has an attraction common to the world, it may be possible to expand sales of the cheaper line-up currently used in advanced nations to an emerging market. In that case, it may be necessary to employ only sales representatives. However, a strategy shift will likely be required when a merchandise and service originate in the lifestyle of the use region and is not spread in partial customisation. Starting a fullscale research and development centre, appointment of the research-and-development able persons of the local, etc., are required in a move-in country. Furthermore, Infrastructure developments, such as a roadway and a railroad, are the solution business for various local problems in the first place. Such businesses should take root in local society in the long run.

In an emerging market, a price-slashing war with a quantity-production industrial article has a thin chance of winning for a Japanese firm. A strategy which fits an emerging country and tackles a settlement of social problems, such as an environmental problem, in the long run will be one of the effective strategies, utilising the component engineering and experience which have been accumulated in Japan. It is thought that a Japanese firm is accepted in a move-in country, improves barriers to entry and imitation difficulty, and can grow continuously by doing so. A CSV strategy which Porter and Kramer (2011) propose will be one of the effective choices which can be taken in a young country for the 
multinational firm of Japan. For long-term social problem solving in such an emerging country, the so-called boundary spanner (Thompson, 1967) will most likely be required. That is, it is well versed in the circumstances of a local society which has scarcely surfaced, and, moreover, a research and development and other statuses of a Japan main office also need to be understood. It is thought that such boundary spanner is transnationalisation of a main office, in short, internationalisation at home. When multinational able persons make the best use of radical trans-activeness (Hart \& Sharma, 2004), it can become possible to use an experience and technical accumulation of Japan as a "problem forward country" for a solution of the social problem of an emerging country.

Therefore, the following hypotheses can be posed about the relationship between transnationalisation of a main office (internationalisation at home) and the advance purpose to an emerging country.

H1. An expansion of the merchandise export to an emerging country and transnationalisation of a main office are unrelated to each other.

H2. A direct investment of the scale-of-production expansion to an emerging country and trans-nationalisation of a main office are unrelated to each other.

H3. A direct investment of the research and development to an emerging country is promoted by trans-nationalisation of a main office.

$\mathrm{H} 4$. A direct investment of the industrial infrastructure exploitation to an emerging country is promoted by trans-nationalisation of a main office.

H5. The effort to solve social problems, such as an environmental problem in an emerging country, is promoted by trans-nationalisation of a main office.

Trans-nationalisation and diversity of a main office may bring about some impacts about the direct investment to emerging countries, such as a development of an industrial infrastructure, and a solution of a social concern. First, the impact is that the company can understand the elusive gaps of the market needs between a developed country and an emerging country, which are pointed out by the precedence research, and lead them to an innovation. Of course, the existing products for developed countries may be accepted in some wealthy class in emerging countries as is. However, in terms of the needs of the volume zone which is the main purchasing power in an emerging country, there are five gaps: performance, infrastructure, sustainability, regulatory, and preferences. Each gap is unclear from the outside, and the adaptation only by the customisation of existing products is insufficient. Research and development of radical new goods and service is needed, applying various component engineering. It is thought that such a destructive innovation can raise customer satisfaction in the volume zone of emerging countries. In order to realise a destructive innovation, it needs a reallocation of resources, organic cooperation, etc., between a parent nation and an advanced country. 
It is thought that reorganisation and cooperation are promoted by lowering the personnelaffairs barrier between a main office and an advanced country.

Moreover, cooperation with local various partners will be likely useful in order to realise such a destructive innovation. It cannot be overemphasised that the notice and cooperation from various partners are useful to the determination of the needs of an emerging country. It is difficult to bring the scheme of a parent nation style together with an industrial infrastructure, laws and regulations, a production and a distribution system, a lifestyle, etc. It is desirable to lower barriers by cooperation with various local partners. By building a good relationship with various local partners, the reliance on the local society and customer satisfaction will be raised. For example, as studies have pointed out, in order to perform the activities which consider the environment in the research and development and production in an emerging country, it is desirable to cooperate with NPO experts in a local environmental problem. By cooperation with an environmental NPO, etc., the suitable valuation and reliance to an activity can be obtained and the continuous local activity will become possible. According to the precedence research, in an emerging country the construction of a relationship with various partners, including the stakeholder who is almost unrelated to the business itself, is important, and the relationship is rather implicit. If the main office of a parent nation cannot understand complicated relationships with such local stakeholders well, suitable decision-making and assistance are difficult. When a parent nation trans-nationalises, it is thought that a settlement of the problems of management is freely promoted across the boundary between a parent nation and an emerging country.

When spreading a business like a development of an industrial infrastructure, especially in an emerging country, a more long-term effort is required as compared with sales of a consumption goods, etc. And the objective is not only expanding the volume of sales of a product. It is increasing the employment in a developing country, raising the standard of living, and reducing environmental impact. According to studies, the value with which Japan should provide an emerging country is a solution proposal of the safety, security, cleanliness, and comfort based on an accumulation of the experience which has overcome past various pollution issues, accidents, disasters, etc. And the result is the norm and standard of the product and service of Japan permeating an emerging country, and intellectual property rights being established and becoming barriers to entry. For example, the solutions expected for emerging countries are a low environmental impact infrastructure and transportation, accuracy, safety, comfortable service, etc. Such a solution proposal is realised with improvement in operation quality, the diffusion of the valuations to an environmental impact, and safety. In order to spread such standard, in addition to the qualified marketing specialist employed in the emerging country, an understanding and positive assistance of a parent nation is useful. Diffusion is supportable when the person from an emerging country gains various experiences in a parent nation and understands the value and the realisation procedure. If such a solution 
can be offered in an emerging country, a long-term competitive advantage and imitation difficulty are established, and a continuous profitability can be attained.

Therefore, the following hypothesis can be derived about the relationship between transnationalisation of a main office (internationalisation at home) and the activity and result in an emerging country.

H6. The alliance with the company in an emerging country is promoted by transnationalisation of a main office.

$\mathrm{H7}$. The alliance with the non-profit organisation in an emerging country is promoted by trans-nationalisation of a main office.

H8. The mergers and acquisitions of a company in an emerging country are promoted by trans-nationalisation of a main office.

H9. The diffusion of the standard of the product and service in an emerging country is promoted by trans-nationalisation of a main office.

$\mathrm{H} 10$. Establishment of the literary property in an emerging country is promoted by transnationalisation of a main office.

$\mathrm{H} 11$. The customer satisfaction in an emerging country increases by trans-nationalisation of a main office.

H12. By trans-nationalisation of a main office, the profitability ratio in an emerging country increases.

\section{Hypothetical verification and consideration}

\section{4-1. The verification procedure}

In order to verify the above-mentioned hypotheses empirically, a questionnaire was given to a company. The multinational firm which has advanced to emerging countries among Japanese firms was set as the target of the questionnaire. A definition of emerging countries here is a criterion of a Ministry of Foreign Affairs, and are Asian nations including China, the countries in Central America, central-and-eastern-Europe countries including Russia, countries in the Middle East, and African countries. The item of the questionnaire was set up based on the above-mentioned hypotheses, and was altogether set to the following Likert scales.

1. Strongly disagree

2. Disagree

3. Neither agree nor disagree

4. Agree

5. Strongly agree 


\section{4-2. Survey synopsis}

The questionnaire was distributed through mail and web to 100 adult graduate students of a business school, in which the author has classes. The number of effective answers which fulfil the above-mentioned conditions and do not have an impairment value of an answer was 52. The survey was conducted in June -August 2014.

\section{4-3. Result of the analysis}

Regarding the effective answer of the questionnaire, the correlation analysis concerned with trans-nationalisation of a main office (internationalisation at home), the advance purpose to an emerging country, activities in an emerging country, and the result in an emerging country was conducted. The correlation analysis was conducted after eliminating the items of which the ceiling or the floor effect are identified on the answers. The statistics analysis used SPSS ver21 made from International Business Machines. A correlation-analysis result is seen in Table. 1. Regarding the subscript of the correlation coefficient in a table, ${ }^{* *}$ shows $1 \%$ of significance level, and ${ }^{*}$ shows $5 \%$ of significance level.

Table 1. Correlation-analysis result

\begin{tabular}{|l|c|}
\hline \multicolumn{1}{|c|}{ Questionaries' item } & correlation \\
& coefficient \\
\hline 1. An expansion of the merchandise export to an emerging country & -.013 \\
\hline $\begin{array}{l}\text { 2. A direct investment of the scale-of-production expansion to an emerging } \\
\text { country }\end{array}$ & -.046 \\
\hline $\begin{array}{l}\text { 3. A direct investment of the research and development to an emerging } \\
\text { country }\end{array}$ & .286 \\
\hline $\begin{array}{l}\text { 4. A direct investment of the industrial infrastructure exploitation to an } \\
\text { emerging country }\end{array}$ & $.444^{* *}$ \\
\hline $\begin{array}{l}\text { 5. The effort to solve social problems, such as an environmental problem in } \\
\text { an emerging country }\end{array}$ & $.523^{* *}$ \\
\hline 6. The alliance with the company in an emerging country & $.461^{* *}$ \\
\hline 7. The alliance with the non-profit organisation in an emerging country & $.411^{*}$ \\
\hline 8. The mergers and acquisitions of a company in an emerging country & .124 \\
\hline
\end{tabular}




\begin{tabular}{|l|c|}
\hline $\begin{array}{l}\text { 9. The diffusion of the standard of the product and service in an emerging } \\
\text { country }\end{array}$ & $.338^{*}$ \\
\hline $\begin{array}{l}\text { 10. Establishment of the literary property in an emerging country } \\
\text { 11. The customer satisfaction in an emerging country }\end{array}$ & $.523^{\star \star}$ \\
\hline \begin{tabular}{l} 
12. The profitability ratio in an emerging country increases. \\
\hline
\end{tabular} & .259 \\
\hline
\end{tabular}

\section{4-4. Consideration}

Based on the above-mentioned correlation-analysis result, the hypothesis about the relationship of trans-nationalisation of a main office (internationalisation at home) and the purpose of the advance into an emerging country is verified first. That is, it is a verification of trans-nationalisation of a main office (internationalisation at home) having progressed because the international business model in the emerging countries of a Japanese firm converted. First, $\mathrm{H} 1$ and $\mathrm{H} 2$ are the hypotheses about the traditional international business model of a Japanese firm. It was verified that the traditional international business model is not correlated with trans-nationalisation of the parent nation.. The parent nation is not trans-nationalised in the traditional international business model of a Japanese multinational firm. When making emerging countries into the low-cost production centre of the merchandise for developed countries, or when exporting the merchandise for developed countries to the wealthy of an emerging country, the workers and sales rep of an emerging country are employed, but it is thought that remote control has been performed about an important management from a parent nation.

Next, H3 to H5 were hypotheses about the new international business model of the Japanese firm in emerging countries. As a result of the correlation analysis, H3 was rejected, and $\mathrm{H} 4$ and $\mathrm{H} 5$ were verified significantly. $\mathrm{H} 4$ to $\mathrm{H} 5$ is the latest international business model in the emerging countries which attract attention. It is a "problem forward country" model which utilises the environmental technology, etc., which the Japanese firm has accumulated, and raises both the social values and enterprise values in emerging countries, and is equivalent to a CSV model. It seems that it was proved that the Japanese multinational firm which is going to adopt such a new international business model, which will concern itself with the community of an emerging country in the long run, was deeply advancing trans-nationalisation of a main office (internationalisation at home). That is, it can be said that the relationship of a transformation of an international business model and trans-nationalisation of a main office (internationalisation at home) became clear. In addition, $\mathrm{H} 3$ was not verified in the correlation analysis. $\mathrm{H} 3$ is a hypothesis about localisation of research and development, and assumed an international business model like a reverse innovation. However, in a traditional international business, the research and development for customising developed- 
countries-oriented merchandise for emerging countries is also carried out, and it is thought that trans-nationalisation of a main office (internationalisation at home) does not necessarily progress in this case.

Next, the hypothesis about the relationship of trans-nationalisation of a main office (internationalisation at home), and the activity and result in an emerging country is verified. First, $\mathrm{H} 6$ to $\mathrm{H} 8$ are hypotheses about the relationship with various stakeholders in an emerging country. Among these, $\mathrm{H} 6$ and $\mathrm{H} 7$, which are the hypotheses about a strategic alliance, were verified. In order to gain a reliance among the various stakeholders of an emerging country, to build a good and intimate relationship and to advance organisational learning, it is thought that trans-nationalisation of a main office (internationalisation at home) is useful. It may be easy to carry out a flexible resource allocation, effective licensing of technology, etc., from a main office by transnationalisation of a main office (internationalisation at home). Besides, $\mathrm{H} 8$ is a hypothesis about mergers and acquisitions, and was rejected. Mergers and acquisitions often constitute the strategy in which a company buys time, and it is thought that mergers and acquisitions which spread the business model of developed countries to an emerging country immediately as it is possible are included. For example, when purchasing the plant and sales network of an emerging country and merely transferring the same operation as a parent nation, a change of the parent company itself may not necessarily be important.

Next, $\mathrm{H} 9$ to $\mathrm{H} 10$ are hypotheses about the diffusion of the standard and administration in an emerging country. Both hypotheses were verified by the correlation analysis. By transnationalisation of a main office (internationalisation at home), it is thought that a standard, an intellectual property administration, etc., can be spread in an emerging country. It may be able to correspond to the real situation of an emerging country's flexibly in terms of a strategy and technique. Moreover, it will be useful to promote relationship construction with stakeholders including various companies, regulatory agencies, and regional governments who can become a partner in an emerging country as mentioned above.

Moreover, $\mathrm{H} 11$ to $\mathrm{H} 12$ are hypotheses about a management result. Among these, $\mathrm{H} 11$ is a hypothesis about the customer satisfaction in an emerging country, and was verified by the correlation analysis. By trans-nationalisation of a main office (internationalisation at home), a company may grasp implicit needs peculiar to an emerging country, understand various and complicated stakeholder relationships, and be able to build the good relationship continuously. And it is thought that the degree of satisfaction of customers or stakeholders in an advanced country can be raised. Further, $\mathrm{H} 12$ is a hypothesis about a profitability ratio, and it did not have a correlation with trans-nationalisation of a parent nation. It is thought that various factors influence a business profit primarily. Moreover, it may take a long time for a new international business model to become fruitful in revenue. The company which is making the profit by the traditional model is likely also included in the respondent. For example, the product and service with a small difference 
between the specification and taste by a country may be able to gain a profit regardless of the diversity of a parent nation.

\section{Conclusion}

The purpose of this study was to quantitatively analyse the relationship between a transformation of an international business model, trans-nationalisation of a main office (internationalisation at home), and the effect on the management in the Japanese multinational firm. It had been pointed out by various studies that trans-nationalisation of the main office (internationalisation at home) of a Japanese firm was not progressing until recently. A contribution of this research is that it is shown empirically that an international business model and diversity management are changing now in a Japanese multinational firm, while corresponding to a transformation of an external environment called extension of an emerging market. Moreover, trans-nationalisation of a main office (internationalisation at home) promoting the alliance in an emerging country, or raising stakeholders' degree of satisfaction, etc., was verified as an effect on management.

As implication of this research, the result may offer the suggestion to the top manager and personnel policy responsible person of a Japanese multinational firm who wants to move in to an emerging country. The limitations of this study are that the number of samples in the questionnaire is small. An emerging-country strategy is considered to vary by type of business, advance place, etc. Since the total number of the sample was not enough, the variance between types of businesses, etc., was not able to be analysed. A future subject is extending a questionnaire object further and conducting a more detailed analysis.

\section{References}

Alesina, A. \& La Ferrara, E. (2005) Ethnic diversity and economic performance. Journal of Economic Literature, 43 (3), 762-800.

Amuro, K. (1982) International-business behaviour theory: The viewpoint of a Japan-U.S. comparison. Moriyama Shoten, Tokyo.

Anderson, S. \& Platzer, M. (2006) American made: The impact of immigrant entrepreneurs and professionals on U.S. competitiveness. National Venture Capital Association study.

Bartlett, C. A. \& Ghoshal, S. (1999) Managing across borders: The transnational solution (Vol. 2). Harvard Business School Press, Boston.

Berliant, M. \& Fujita, M. (2011) The dynamics of knowledge diversity and economic growth. Southern Economic Journal, 77, 856-884.

Berliant, M. \& Fujita, M. (2012) Culture and diversity in knowledge creation. Regional Science and Urban Economics, 42, 648-662.

Bradach, J. L. \& Eccles, R. G. (1989) Price, authority, and trust: From ideal types of plural forms. Annual Review of Sociology, (15), 97-118.

Cervantes, M. \& Guellec, D. (2002) The brain drain: Old myths, new realities. OECD Observer, Paris. 
Chaloff, J. \& Lemaitre, G. (2009) Managing highly-skilled labour migration: A comparative analysis of migration policies and challenges in OECD countries. OECD Social Employment and Migration Working Papers, 79 Paris.

Das, T. K. \& Teng, B. S. (2000) A resource-based theory of strategic alliances. Journal of Management, 26 (1), 31-61.

De Cieri, H. \& Dowling, P. J. (2006) Strategic international human resource management in multinational enterprises: Developments and directions. In: Stahl, G. \& Björkman, I. (eds.) Handbook of research in international human resource management. Cheltenham, UK, Edward Elgar, pp.15-35.

De Cieri, H., Cox, J. W. \& Fenwick, M. S. (2001) Think global, act local: From naïve comparison to critical participation in the teaching of strategic international human resource management, Tamara Journal of Critical Postmodern Organization Science, 1 (1), 68-79.

Dickmann, M. \& Müller-Camen, M. (2006) A typology of international human resource management strategies and process. The International Journal of Human Resource Management, 17 (4), 580-601.

Dowling, P. J. (1988) International human resource management. In: Dyer, L. (ed.) Human resource management: Evolving roles and responsibilities. Washington, DC, ASPA/BNA Handbook of Human Resource Management Series, pp. 228-257.

Dowling, P. J. (1999) "Completing the puzzle: Issues in the development of the field of international human resource management. Management International Review, 39 (3), 27-43.

Doz, Y., Santos, J. \& Williamson, P. (2004) Is your innovation process global? MIT Sloan Management Review, 45 (4), 31-37.

Dunning, J. H. (1979) Explaining changing patterns of international production: In defense of the eclectic theory. Oxford Bulletin of Economics and Statistics, November, 259-269.

Franko, L. G. (1973) Who manages multinational enterprises. The International Executive, 15(3), pp. 20-21.

Freeman, R. E. (2006) People flows in globalization. Journal of Economic Perspectives, 20 (2), 145-170.

Freeman, R. E., Wicks, A. C. \& Parmar, B. (2004) Stakeholder theory and the corporate objective revisited. Organization Science, 15 (3), 364-369.

Frost, T. S., Birkinshaw, J. M. \& Ensign, P. C. (2002) Centers of excellence in multinational corporations. Strategic Management Journal, 23 (11), 997-1018.

Fukao, K. (2006) The Japanese firm which is delayed in localization. Economic Classroom, Nihon Keizai Shimbun, 2006-7-5, pp.33.

Giovanni, P. (2007) Higher education, innovation and growth. In: Brunello, G., Garibaldi, P. and Wasmer, E. (eds.) Education and training in Europe. Oxford, Oxford University Press, pp. 56-70.

Govindarajan, V. \& Trimble, C. (2012) Reverse innovation: A global growth strategy that could pre-empt disruption at home. Strategy \& Leadership, 40 (5), pp. 5-11.

Gregersen, H. B. \& Black, J. S. (1996) Expatriate performance appraisal in U. S. multinational firms. Journal of International Business Studies, 27 (4), 711-738.

Hall, E. T. (1976) Beyond Culture. Anchor. Garden City, NY.

Hart, S. L. \& Sharma, S. (2004) Engaging fringe stakeholders for competitive imagination. Academy of Management Executive, 18 (1), 7-18.

Hartman, C. L. \& Stafford, E. R. (1997) Green alliances: Building new business with environmental groups. Long Range Planning, 30 (2), 184-196.

Harzing, A. W. (2001) Who's in charge?: An empirical study of executive staffing practices in foreign subsidiaries. Human Resource Management, 40 (2), 139-158. 
Hayashi, K. (1994) Cultural interface management: An internationalization and Japanese management. Nihon Keizai Shimbun, Tokyo.

Herring, C. (2009) Source does diversity pay?: Race, gender, and the business case for diversity. American Sociological Review, 74 (2), 208-224.

Hunt, J. \& Gauthier-Loiselle, M. (2010) How much does immigration boost innovation? American Economic Journal: Macroeconomics, 2 (2), 31-56.

Hunter, R., Oswald, A. \& Charlton, B. (2009) The elite brain drain. The Economic Journal 119, F231-F251.

Hymer, S. H. (1970) The efficiency (contradictions) of multinational corporations. The American Economic Review, 60 (2), 441-448.

Immelt, J. R., Govindarajan, V. \& Trimble, C. (2009) How GE is disrupting itself. Harvard Business Review, 87 (10), 56-65.

Inkpen, A. C. (1998) Learning, knowledge acquisition, and strategic alliances. European Management Journal, 16 (2), 223-229.

loannidis, J. P. A. (2004) Global estimates of high-level brain drain and deficit. The Journal of the Federation of American Societies for Experimental Biology, 18, 936-939.

Japanese Business Federation (2011) The proposal towards global able persons' training. [Online] Available from: https://www.keidanren.or.jp/, accessed 08-11-2013.

Kamata, H. (2006) International comparison: The management of a Japanese firm in Thailand. Japan Center for Economic Research.

Kerr, W. R. (2008) The ethnic composition of US inventors. Harvard Business School Working Paper, 08006.

Kerr, W. R. (2010a) The agglomeration of U.S. ethnic inventors. In: Glaeser, E. (ed.) Agglomeration Economics. Chicago, University of Chicago Press, pp. 237-276.

Kerr, W. R. (2010b) Breakthrough inventions and migrating clusters of innovation. Journal of Urban Economics, 67, 46-60.

Kerr, W. R. \& Lincoln, W. (2010) The supply side of innovation: H-1B visas and US ethnic invention. Journal of Labor Economics, 28 (3), 473-508.

Komiyama, H. (2007) Japan as a forerunner for addressing emerging problems in the world. Tokyo, Chuokoron-Sha.

Larson, A. (1992), Network dyads in entrepreneurial settings: A study of the governance of exchange relationships. Administrative Science Quarterly, (37), 76-103.

Lee, N. \& Nathan, M. (2010) Knowledge workers, cultural diversity and innovation: Evidence from London. International Journal on Knowledge Based Development, 1 (1-2), 53-78.

London, T. \& Hart, S. L. (2004) Reinventing strategies for emerging markets: Beyond the transnational model. Journal of International Business Studies, (35), 350-370.

Maré, D. C., Fabling, R. \& Stillman, S. (2011) Immigration and innovation. Bonn, IZA Institute for the Study of Labor.

Mendleson, N. \& Polonsky, M. J. (1995) Using strategic alliances to develop credible green marketing. Journal of Consumer Marketing, 12 (2), 4-18.

Morgan, P. V. (1986) International HRM: Fact or fiction? Personnel Administrator, 31 (9), 43-47.

Niebuhr, A. (2010) "Migration and innovation: Does cultural diversity matter for regional R\&D activity? Papers in Regional Science, 89, 563-585. 
Niebuhr, A. \& Peters, C. (2012) Labour diversity and firm's innovation: Evidence from Germany. Nuremburg, IAB Institute for Employment Research.

Nonaka, T. (2004) Localization of a Japanese firm important at the Chinese market advance. IT solution frontier, Nomura Research Institute.

Oddou, G. R., Gregersen, H. B., Black, J. S., \& Derr, B. D. (2001) Building global leaders: Strategy similarities and differences among European, U. S., and Japanese multinationals. In: Mendenhall, M. E., Kuhlmann, T. M. \& Stahl, G. K. (eds.) Developing global business leaders: Policies, processes, and innovations. Quorum Books, Westport, CT, pp.99-116.

OECD (2013) International migration outlook 2013. Paris, OECD.

Østergaard, C. R., Timmermans, B. \& Kristinsson, K. (2011) Does a different view create something new?: The effect of employee diversity on innovation. Research Policy, 40, 500-509.

Ottaviano, G. \& Peri, G. (2006) The economic value of cultural diversity: Evidence from US cities. Journal of Economic Geography, 6, 9-44.

Ozgen, C., Nijkamp, P. \& Poot, J. (2011) Immigration and innovation in European regions. IZA Discussion Paper Series, 5676.

Ozgen, C., Nijkamp, P. \& Poot, J. (2012) Immigration and innovation in European regions. In: Poot, J., Nijkamp, N. \& Sahin, M. (eds.) Migration impact assessment: New horizons. Edward Elgar Publishing, Cheltenham, pp. 261-299.

Ozgen, C., Nijkamp, P. \& Poot, J. (2013), Measuring cultural diversity and its impact on innovation: Longitudinal evidence from Dutch firms. IZA Discussion Paper Series, 7129.

Parotta, P., Pozzoli, D. \& Pytlikova, M. (2011) The nexus between labour diversity and firm's innovation. Norface Migration Discussion Paper, 2011-5.

Peri, G. (2007) Higher education, innovation and growth. In: Garibaldi, P., Brunello, G. \& Wasmer, E. (eds.) Education and training in Europe. Oxford, Oxford University Press, pp. 56-70.

Porter, M. E. \& Kramer, M. R. (2011) The big idea: Creating shared value. How to reinvent capitalism - and unleash a wave of innovation and growth. Harvard Business Review, 89 (1-2), 62-77.

Shiraki, M. (2006) The comparative analysis of international human resource administration. Yuhikaku Publishing, Tokyo.

Spekman, R. E., Forbes, T. M., Isabella, L. A. \& MacAvoy, T. C. (1998) Alliance management: A view from the past and a look to the future. Journal of Management Studies, 35 (6_, 747-772.

Stafford, E. R. \& Hartman, C. L. (1996) Green alliances: Strategic relations between businesses and environmental groups. Business and Horizons, March-April, 50-59.

Stephan, P. \& Levin, S. (2001) Exceptional contributions to US science by the foreign-born and foreigneducated. Population Research and Policy Review, 20 (1-2), 59-79.

Südekum, J., Wolf, K. \& Blien, U. (2009) Cultural diversity and local labour markets. IZA Discussion Paper 4619. Bonn, IZA Institute for the Study of Labor.

Suzuki, I. (2005) The core personnel training of a foreign-fund company in China: At a comparison with United States, Taiwan, the South Korean and Japanese company. Socio-economic Research Centre, Wako University.

Thompson, J. D. (1967) Organizations in action: Social science bases of administrative theory. Transaction Publishers, New Brunswick, N.J.

Wadhwa, V., Saxenian, A., Rissing, B. \& Gereffi, G. (2007) America's new immigrant entrepreneurs. Kauffman Foundation Report. 
Yoshiwara, H. (1989) Local president and internationalization at home: The new paradigm of transnationalization. The Journal of Business Management, 58, 86-94.

Zucker, L. G. \& Darby, M. R. (2007) Star scientists, innovation and regional and national immigration. NBER Working Paper, 13547. 